\title{
The role of B cells in systemic sclerosis
}

\author{
Marina D Kraaij \\ Jacob M van Laar
}

Musculoskeletal Research Group, Institute of Cellular Medicine, School of Clinical Medical Sciences, Newcastle University, Newcastle upon Tyne NE2 4HH, United Kingdom
Correspondence: Jacob M van Laar Professor of Clinical Rheumatology, Musculoskeletal Research Group, Institute of Cellular Medicine, 4th Floor, Catherine Cookson Building, The Medical School, Framlington Place, Newcastle University, Newcastle upon Tyne NE2 4HH,

United Kingdom

Tel +44 I9| 2227139

Fax +44 I9। 2225455

Email j.m.van-laar@ncl.ac.uk
Abstract: Systemic sclerosis (SSc) is a connective disease characterized by features of autoimmunity, vasculopathy, inflammation, and fibrosis. The disease typically starts with Raynaud's phenomenon, followed by skin thickening in the extremities due to inflammation and fibrosis. Fibrosis results from excessive collagen production by fibroblasts, which constitutes the final common pathway of complex cellular interactions including B cells. Several studies have indicated that B cells may play a role in SSc. Lesional skin infiltrates from SSc patients consist of a variety of cells, including eosinophils, neutrophils, lymphocytes, plasma cells, and macrophages. Autoantibodies of several specificities are present in the serum of SSc patients of which antitopoisomerase 1 is the most common, and evidence has been gathered for a potential pathogenic role of some autoantibodies, eg, anti-PDGF antibodies. The blood of SSc patients contains an increased proportion of naïve B cells but a decreased proportion of memory B cells. Furthermore, serum levels of interleukin-6, an important pro-inflammatory cytokine, have been shown to correlate with skin fibrosis. Animal models of SSc have provided more in-depth information on the role of B lymphocytes, eg, through disruption of B cell function. In this review we will discuss the evidence that $\mathrm{B}$ cells are involved in the pathogenesis of SSc.

Keywords: B lymphocyte, systemic sclerosis, fibrosis

\section{Introduction}

Systemic sclerosis (SSc) is a systemic autoimmune, connective tissue disease characterized by inflammation, vascular endothelial dysfunction, specific immunologic abnormalities, and tissue fibrosis due to an imbalance between collagen production and degradation. Although its phenotypic characteristics are heterogeneous and disease course variable, two different clinical subtypes can be identified, the limited cutaneous form (1SSc) and the diffuse cutaneous form of SSc (dSSc). The 1SSc subset is characterized by skin thickening of the face, neck, and distal aspects of the limbs, by ischemic digital loss, and an increased prevalence of isolated pulmonary hypertension. The dSSc subset involves skin of the proximal limbs as well and affects visceral organs, including the lung, heart, gastrointestinal tract, and kidneys, especially at late stages. The prevalence of SSc in females is higher than in males and in blacks than in whites (Mayes et al 2003). The average age at diagnosis is lower for blacks than for whites, and blacks have about a twice higher chance to develop dSSc. A positive family history is the strongest risk factor for SSc, although the absolute risk for each family member remains low (Arnett et al 2001).

SSc is believed to be caused by the interaction of genetic and environmental factors (Jimenez and Derk 2004; Abraham and Varga 2005; Denton and Black 2005), leading to a loss of immune tolerance. T and B lymphocytes are responsible for the establishment and maintenance of tolerance as illustrated by the observation that alterations in B cell signaling result in autoimmunity. B cell signaling is modulated by response regulators, such as CD19 (Goodnow 1996; Conrad et al 2007). For example, combined binding of CD19 with the antigen-receptor of B lymphocytes decreases the antigen receptor-stimulation threshold a 100-fold (Carter and Fearon 1992). CD19 can also 
form a complex with CD21, the receptor for fragments of the third complement component (C3), which amplifies the BCR-signal. This binding of C3 to the CD19-CD21 complex links innate with humoral immunity (Tedder et al 1997). CD22 is a negative regulator of the BCR complex, terminating signal transduction (Asano et al 2004). Both CD19 and CD22 have their own regulatory network for the BCR complex; CD19 expression causes CD22 phosphorylation, while CD22 expression is responsible for the inhibition of CD19 (Fujimoto et al 1999; Fujimoto and Sato 2007). This CD19/CD22 loop suggests a regulation-balance of autoimmunity in B cells. In keeping with this, transgenic mice overexpressing CD19 showed increased serum levels of autoantibodies, indicating that CD19 overexpression disrupts tolerance in B cells (Inaoki et al 1997). Interestingly, CD22 deficient mice also had increased levels of autoantibodies indicating that $\mathrm{CD} 22$ deficiency alone is sufficient to induce autoimmunity (O’Keefe et al 1999).

Whatever the precise abnormal immunological mechanism underlying SSc, the aforementioned studies do illustrate how subtle B cell abnormalities lead to survival and activation of self-reactive B cells, production of autoantibodies and autoimmune disease (Lipsky 2001; Youinou 2007).

\section{Pathological features of SSc}

Dermal fibrosis typically starts in the extremities with an inflammatory phase characterized by mononuclear infiltration (Fleischmajer et al 1983), which will then progress to fibrosis. Although the exact process is not known, it is suggested that as inflammation subsides, fibrosis increases (Sakkas 2005). In the skin, thickening of the dermis is found showing accumulation of dense collagen, whereas in the lower dermis small vessels showed fibrous thickening (Fleischmajer et al 1977; Jiminez and Derk 2004). An early study on skin biopsies, using hematoxylin and eosin (H\&E) stainings, showed cellular infiltrates consisting of lymphocytes, plasma cells, and macrophages in $49 \%$ of $65 \mathrm{SSc}$ patients (Fleischmajer et al 1977). Hussein and colleagues (2005) confirmed the presence of increased numbers of histiocytes, eosinophils, and neutrophils in lesional skin of patients with SSc compared with the normal skin of healthy controls using H\&E stainings. Of note, immunohistochemical (IHC) analysis showed no $\mathrm{CD} 20^{+} \mathrm{B}$ cells in these patients. A recent study, however, did show $\mathrm{CD} 20^{+} \mathrm{B}$ cells in 3 skin biopsies from 8 control SSc patients, although in the skin biopsies from 4 SSc patients treated with anti-CD20 monoclonal antibody no CD20 ${ }^{+}$ $B$ cells were detected. $C D 3^{+} \mathrm{T}$ cells were found in all tissue samples (Bosello et al 2007). In our own hands abundant expression of CD79a $\mathrm{a}^{+} \mathrm{B}$ cells can be detected in the dermis of SSc patients (Figure 1). A mononuclear infiltrate was also detected by others using IHC in pulmonary tissue samples from SSc patients with interstitial lung disease (ILD) showing the presence of $\mathrm{CD} 20^{+} \mathrm{B}$ cells, $\mathrm{CD} 3^{+} \mathrm{T}$ cells, and CD68 ${ }^{+}$ macrophages (Lafyatis et al 2007). Plasma cells were not stained in this study. A gene expression study on SSc skin samples provided further evidence for a prominent role of B cells (Whitfield et al 2003). Gene clusters involving groups of genes characteristically expressed in endothelial cells, B lymphocytes, those associated with synthesis of extracellular matrix, and genes expressed in T cells were highly expressed in tissue from the SSc patients when compared to healthy controls. Gene expression from skin biopsies showed prominent gene expression (immunoglobulins and CD53 genes) associated with B-lymphocytes, including plasma cells, indicating that the mononuclear cell infiltrates consist of a variety of cells.

\section{Autoantibodies in SSc}

Autoantibodies are present in $95 \%$ of SSc patients, and are either specific for SSc or have overlap with other connective diseases (Meyer 2006). The autoantibodies antitopoisomerase 1 (anti-Topo 1, Scl-70), anti-RNA polymerase III, and anti-U3 RNP are associated with dSSc, whereas others, like anticentromere, anti-U1 RNP, anti-PmScl, and anti-Th/To are associated with 1SSc. The incidence rates of these autoantibodies vary among different ethnic groups (Kuwana et al 1999; Reveille et al 2001). In a study of 1,432 cases from the Pittsburgh Scleroderma Databank, 10-year survival was linked to autoantibody status. In patients with ISSC the 10 -year survival was $75 \%$ in patients positive for anticentromere antibody, $88 \%$ for those with anti-U1 RNP, $72 \%$ in those with anti-PmScl, and $65 \%$ in patients with anti-Th/To autoantibodies. For dSSC patients the 10-year survival was $64 \%$ for patients with anti-Topo $1,75 \%$ for patients with anti-RNA polymerase III, and $61 \%$ in those with anti-U3 RNP autoantibodies (Steen 2005). Different autoantibodies are associated with different clinical manifestations. ILD is associated with anti-Topo 1, pulmonary hypertension with anticentromere antibodies, anti-3U RNP, and anti$\mathrm{Th} / \mathrm{To}$, whereas renal hypertension is associated with RNA polymerase III antibodies (Meyer 2006).

Anti-Topo1 is the most common autoantibody (10\%-30\%) in dSSc (Tan et al 1988; Kuwana et al 1994). Its serum levels correlate positively with disease activity and disease severity in SSc (Hu 2003). Moreover, loss of anti-Topo 1 has been associated with clinical improvement (Kuwana et al 2000). 

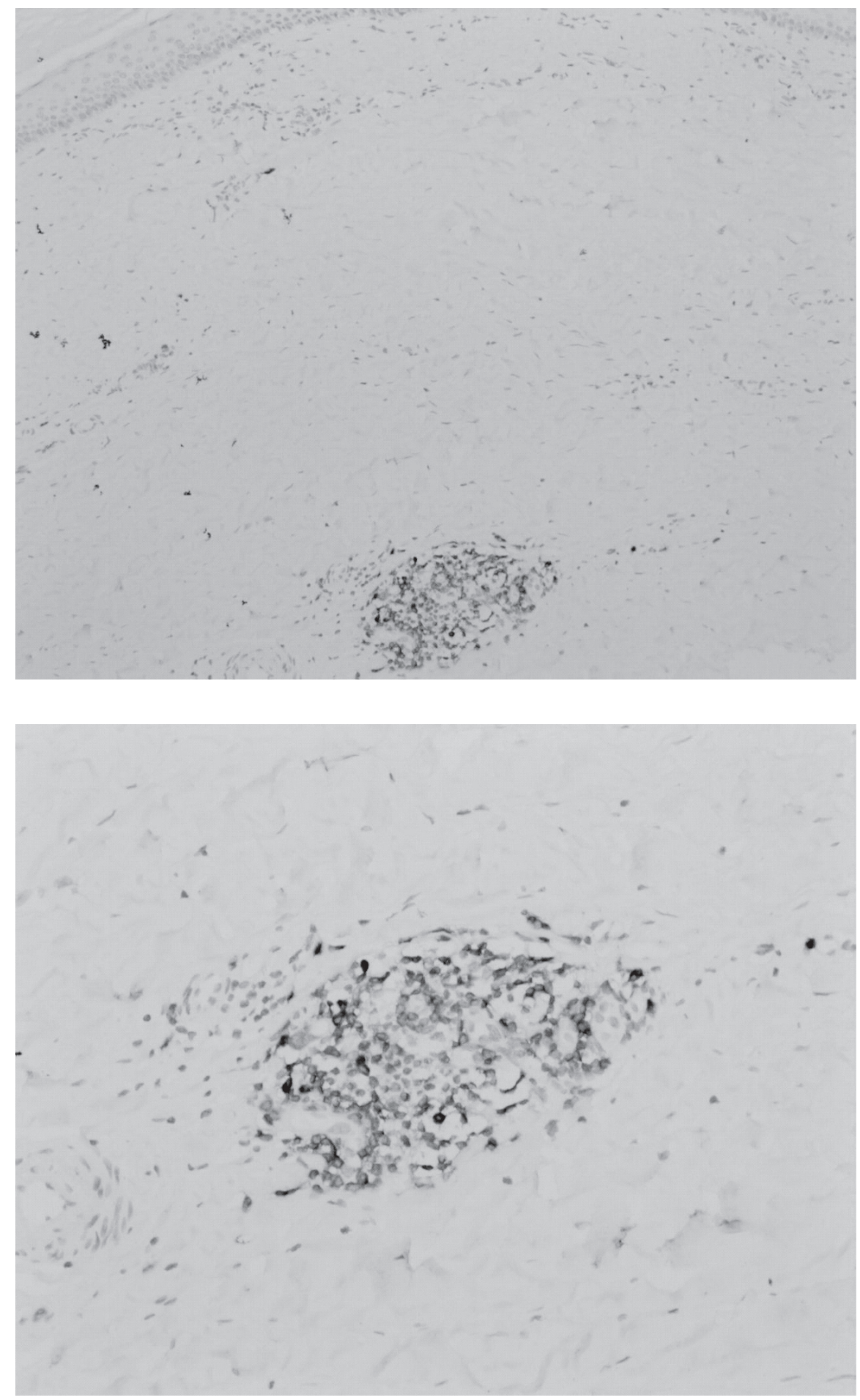

Figure I CD79a+ B cell infiltrate in dermis of patient with systemic sclerosis (paraffin section, 100x magnification upper figure, 200x magnification lower figure).

More recently, other autoantibodies have been detected in the sera of SSc patients (Arnett 2006). These include antiendothelial cell antibodies (AECAs), antifibrillin-1 (antiFBN1) antibodies, antibodies against matrix metalloproteinases (MMP), and antiplatelet-derived growth factor receptor (PDGFR) antibodies. Some of the AECAs have been shown to bind to the human cytomegalovirus late protein UL94, and induce endothelial cell apoptosis via the interaction with the cell surface integrin-NAG-2 protein complex (Lunardi et al 2000). Anti-FBN1 antibodies activate normal fibroblasts resulting in the increased production of ECM components (Zhou et al 2005). Anti-PDGFR autoantibodies induce 
collagen 1 production by reactive oxygen species cascades, and convert resting fibroblasts into myofibroblasts (Baroni et al 2006). Further autoantibodies found in SSc patients include antifibroblast antibodies (AFA), which are capable of binding to the surface of fibroblasts (Chizzolini et al 2002), and autoantibodies against the molecular chaperone heat-shock protein 47 (HSP47) (Fujimoto et al 2004). The presence of circulating, potentially functional, autoantibodies argues in favor of a pathogenic role of B cells in SSc.

\section{Other immunological abnormalities in SSc}

B cells, among other cells, secrete interleukin-6 (IL-6), which stimulates fibroblasts to produce collagen. In a mouse scleroderma model, B cell depletion using an anti-mouse CD20 monoclonal antibody led to a decrease in IL-6 mRNA levels and a reduction of fibrosis (Hasegawa et al 2006). IL-6 serum levels and spontaneous IL-6 production by peripheral blood mononuclear cells (PBMCs) are higher in SSc patients compared with normal controls. In addition, it was shown that IL-6 serum levels correlate with skin fibrosis (Sato et al 2001). Thus, IL-6 may be an important target for the treatment of SSc in humans. Other cytokines may also be involved. In SSc patients elevated levels of IL-4, IL-8, IL-10, IL-12, IL-13, and IL-17 were found, suggesting that both $\mathrm{B}$ and $\mathrm{T}$ cells are involved in the pathogenesis of SSc (Hasegawa et al 1997; Kurasawa et al 2000; Sato et al 2000a; Furuse et al 2003). The CD4+ Thelper cells 2 (Th2) cytokines IL-4, IL-6, and IL-13 stimulate the synthesis of collagen by fibroblasts, leading to excessive scar formation and fibrosis (Duncan and Berman 1991; Wynn 2004). One of the key cytokines involved in tissue fibrosis is transforming growth factor- $\beta$ (TGF- $\beta$ ) (Varga and Abraham 2007). Human B lymphocytes, amongst other cells, can be a source of TGF- $\beta$ and express receptors for TGF- $\beta$ (Kerhl et al 1986). TGF- $\beta$ promotes collagen deposition and inhibits collagen degradation by decreasing MMPs and increasing the tissue inhibitors of metalloproteinases (TIMP) expression (Verrecchia et al 2007). Serum TIMP-1, but not MMP-1 levels, are elevated in SSc patients compared with normal controls, indicating that collagen accumulation results from inhibition rather than a decrease in MMPs (Young-Min et al 2001).

Flowcytometric analysis of peripheral blood mononuclear cells from SSc patients showed an increased number of naïve B cells, but a decreased number of memory B cells and plasmablasts (Sato et al 2004). CD19 expression was increased in both naïve and memory B cells, but only memory B cells had an activated phenotype with increased expression of CD80, CD86, and CD95 suggesting chronic activation. Another study showed a 20\% higher CD19 and CD21 cell surface density in blood samples from SSc patients compared with normal controls, but similar expression levels of CD20, CD22, and CD40 (Sato et al 2000b). SSc patients have elevated levels of B lymphocyte stimulator (BAFF) (Matsushita et al 2006). SSc B cells showed increased levels of BAFF receptor (BAFFR) as well, indicating a pathogenic role of B cells caused by BAFF. BAFF combined with BCR ligation stimulates $B$ cell activity, and was shown to rescue some self-reactive B cells from death (Schneider et al 1999; Thien et al 2004). Another role of BAFFR is the upregulation of Bcl-2 expression as well as nuclear factor kappa-B (NF-KB) activation, favoring B cell survival (Do et al 2000). These studies indicate that BAFF might promote the survival of B cells, thereby contributing to autoimmunity in SSc.

\section{Animal models of SSc}

There are several mouse models with features of SSc (summarized in Table 1). The University of California, Davis (UCD) line 200 chickens have numerous immunopathologic and serologic features in common with human scleroderma (Gershwin et al 1981). As early as 7 days, lymphocytic infiltration with $\mathrm{T}$ and $\mathrm{B}$ cells, followed by fibrosis and

Table I Overview of animal models of scleroderma and comparison with immunological and clinical features of human scleroderma

\begin{tabular}{|c|c|c|c|c|c|}
\hline & Human scleroderma & GVH SSc in BALB/c mice & UCD-200 chickens & $\begin{array}{l}\text { Bleomycin-induced } \\
\text { scleroderma }\end{array}$ & TSK/+ mice \\
\hline Autoantibodies & + & + & + & + & + \\
\hline Vasculopathy & + & + & + & - & + \\
\hline \multicolumn{6}{|l|}{ Fibrosis } \\
\hline Skin & + & + & + & + & + \\
\hline Internal & + & + & + & + & - \\
\hline Inflammation & + & + & + & + & - \\
\hline
\end{tabular}

Abbreviations: GVH SSc, graft-versus-host systemic sclerosis;TSK, tight-skin; UCD, University of California, Davis. 
vascular occlusion of the skin, feet, and comb can be observed (Van de Water et al 1989; Gruschwitz et al 1991) Infiltration of $\mathrm{CD}^{+}$cells precedes that of $\mathrm{CD}^{+}$and $\mathrm{B}$ cells, but during maturation of the skin lesion B cell clusters increase in size, and in mature lesions distinct $\mathrm{B}$ and $\mathrm{T}$ cell areas are recognized. Also antinuclear antibodies, antibodies to collagen and rheumatoid factor can be detected in this model, as well as antiendothelial cell antibodies (Sgonc et al 1996).

In another model, the injection of bleomycin into the skin of mice results in histological dermal changes with thickened and homogenous collagen bundles and cellular infiltrates consisting mainly of $\mathrm{CD}^{+}$lymphocytes, mast cells and macrophages similar to human scleroderma skin. Bleomycin treatment also leads to the production of serum autoantibodies (Yamamoto et al 1999; Yamamoto 2006). In MRL/lpr mice deficient for interferon-gamma (IFN- $\gamma$ ) (MRL/lpryR-/-) histological changes are described resembling human scleroderma, such as accumulation of collagen and mononuclear cell infiltration with $\mathrm{T}$ and $\mathrm{B}$ cells, and macrophages in connective tissue of several organs as well as intima thickening (Le Hir et al 1999).

The tight-skin (TSK) mouse is a third model of SSc, and although it does not share all its phenotypic characteristics, autoantibodies are found against SSc-specific target autoantigens including Topo I, fibrillin 1 (Fbn-1), RNA polymerase I, collagen type I, and Fc $\gamma$ receptors (Bona and Rothfield 1994). It is believed that the TSK phenotype is caused by an internal duplication within the fibrillin 1 gene, resulting in a $3 \mathrm{~kb}$ larger transcript compared with the wildtype transcript (Siracusa et al 1996). Mice homozygous for this mutation die in utero, while heterozygous (TSK/+) mice survive and develop cutaneous fibrosis, pulmonary emphysema, and cardiac hypertrophy (Saito et al 2000; Fujimoto and Sato 2007). The immunological abnormalities are not well understood, however. The infusion of bone marrow cells of $\mathrm{TSK} / \mathrm{pa}$ mice into $\mathrm{pa} / \mathrm{pa}$ littermates resulted in sclerodermalike skin changes with thickening of the deep dermis and a diffuse, interstitial mononuclear infiltrate, consisting of activated lymphocytes, plasma cells and activated macrophages three months later, preceded by a rise in anti-RNA polymerase 1 and Topo 1 autoantibodies (Phelps et al 1993). In another study in the TSK/+ mouse model it was shown that CD19 deficiency resulted in reduction of skin thickness in these mice (Saito et al 2002). Due to this deficiency, IL-6 production by TSK/+ B cells as well as autoantibody production in TSK/+ mice was decreased, showing that there is a CD19 dependent signalling pathway in B cells contributing to systemic autoimmunity and skin sclerosis in TSK/+ mice.

A more recent mouse model has been a modified model of graft-versus-host (GVH)-induced SSc. The injection of spleen

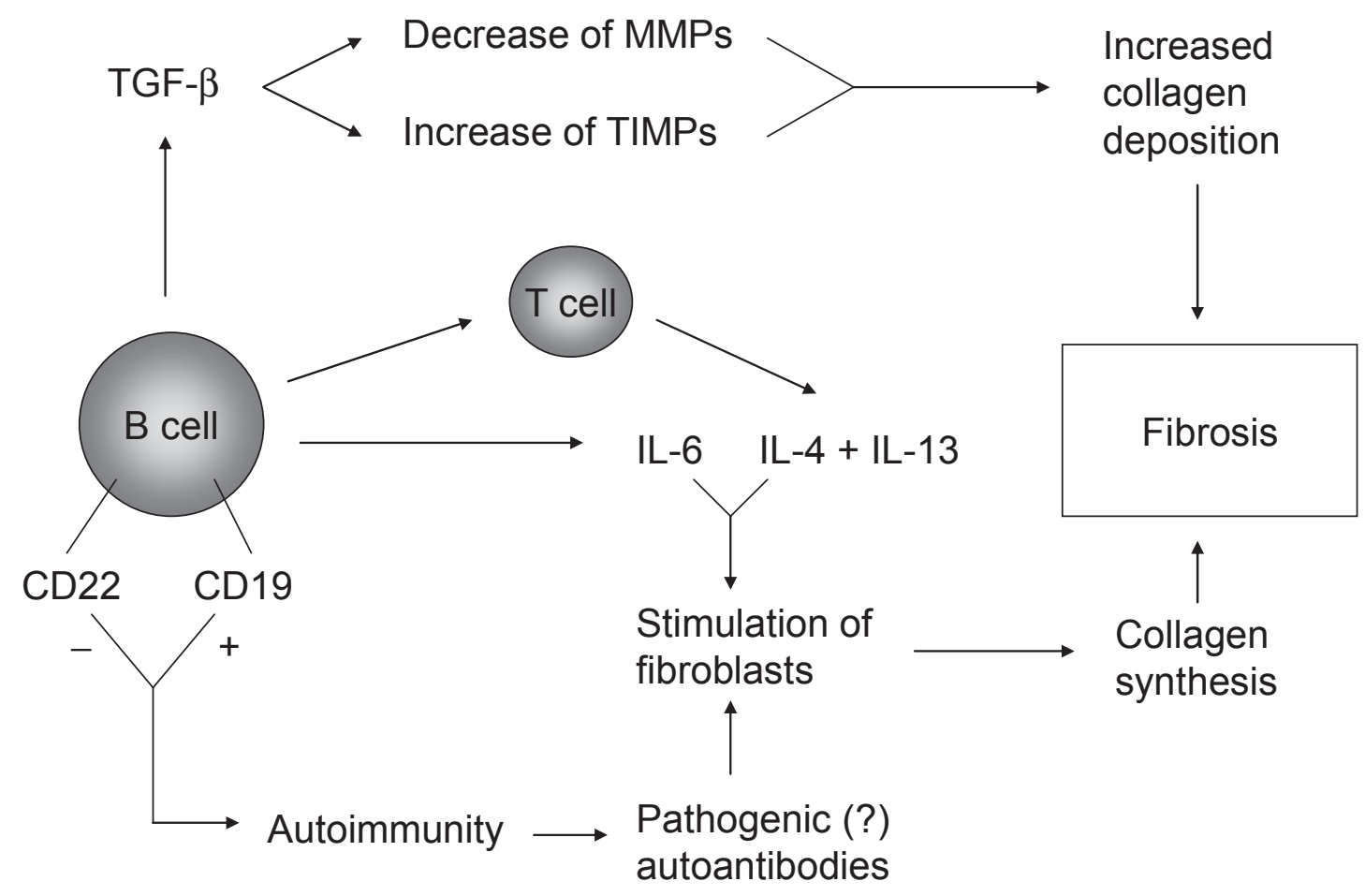

Figure 2 Potential pathways through which B cells mediate or contribute to fibrosis. 
cells from B10.D2 mice into BALB/c mice deficient in mature $\mathrm{T}$ and $\mathrm{B}$ cells induces a disease resembling SSc with dermal thickening, progressive fibrosis in internal organs, vasculopathy, and presence of autoantibodies (Ruzek et al 2004).

\section{Summary}

The findings from a number of (pre)clinical studies point to a potential role for B lymphocytes in the pathogenesis of systemic sclerosis. These include abnormal B cell signalling in TSK/+ mice, the presence of B cells and expressed B cell genes in skin biopsies from SSc patients, abnormalities in numbers and activation status of B cells in peripheral blood, the presence of serum autoantibodies and elevated serum levels of cytokines such as IL-6 which correlate with skin fibrosis. B cells could contribute to fibrosis through several mechanisms, depicted in Figure 2. The stage is set for clinical trials to investigate whether B cell depletion in SSc is effective as in other autoimmune diseases (Looney 2002; Browning 2006; Blank and Shoenfeld 2007). Preliminary results from a pilot study in SSc patients with rituximab, a chimeric anti-CD20 monoclonal antibody are encouraging (Bosello et al 2007).

Nevertheless, our understanding of the precise contribution of B lymphocytes in the early stages in the pathogenesis of systemic sclerosis is limited, and some of the evidence circumstantial. Further studies are therefore needed to dissect the specific contribution of B lymphocytes in the pathogenesis of systemic sclerosis.

\section{Disclosure}

The authors declare no conflict of interest.

\section{References}

Abraham DJ, Varga J. 2005. Scleroderma: from cell and molecular mechanisms to disease models. Trends Immunol, 26:587-95.

Arnett FC, Cho M, Chatterjee S, et al. 2001. Familial occurrence frequencies and relative risks for systemic sclerosis (scleroderma) in three United States cohorts. Arthritis Rheum, 44:1359-62.

Arnett FC. 2006. Is scleroderma an autoantibody mediated disease? Curr Opin Rheum, 18:579-81.

Asano N, Fujimoto M, Yazawa N, et al. 2004. B Lymphocyte signaling established by the CD19/CD22 loop regulates autoimmunity in the tight-skin mouse. Am J Path, 165:641-50.

Baroni SS, Santillo M, Bevilacqua F, et al. 2006. Stimulatory autoantibodies to the PDGF receptor in systemic sclerosis. $N$ Eng $J$ Med, 354:2667-76

Blank M, Shoenfeld Y. 2007. B cell targeted therapy in autoimmunity. J Autoimmun, 28:62-8.

Bona C, Rothfield N, 1994. Autoantibodies in scleroderma and tightskin mice. Curr Opin Immunol, 6:931-7.

Bosello S, De Santis M, Lama G, et al. 2007. Clinical improvement in systemic sclerosis patients treated with anti-CD20 [abstract]. Arthritis Rheum, 1223.

Browning JL. 2006. B cells move to centre stage: novel opportunities for autoimmune disease treatment, Nat Rev Drug Discov, 5:564-76.
Carter RH, Fearon DT. 1992. CD19: lowering the threshold for antigen receptor stimulation of B lymphocytes. Science, 256:105-7.

Chizzolini C, Raschi E, Rezzonico R, et al. 2002. Autoantibodies to fibroblasts induce a proadhesive and proinflammatory fibroblast phenotype in patients with systemic sclerosis. Arthritis Rheum, 46:1602-13

Conrad FJ, Rice JS, Cambier JC. 2007. Multiple paths to loss of anergy and gain of autoimmunity. Autoimmunity, 40:418-24.

Denton CP, Black CM. 2005. Targeted therapy comes of age in scleroderma. Trends Immun, 26:596-602.

Do RK, Hatada E, Lee H, et al. 2000. Attenuation of apoptosis underlies B lymphocyte stimulator enhancement of humoral immune response. J Exp Med, 192:953-64.

Duncan MR, Berman B. 1991. Stimulation of collagen and glycosaminoglycan production in cultured human adult dermal fibroblasts by recombinant human interleukin 6. J Invest Dermatol, 97:686-92.

Fleischmajer R, Perlish JS, Reeves JR. 1977. Cellular infiltrates in scleroderma skin. Arthritis Rheum, 20:975-84.

Fleischmajer R, Perlish JS, Duncan M. 1983. Scleroderma. A model for fibrosis. Arch Dermatol, 119:957-62.

Fujimoto M, Bradney AP, Poe JC, et al. 1999. Modulation of B lymphocyte antigen receptor signal transduction by a CD19/CD22 regulatory loop. Immunity, 11:191-200

Fujimoto M, Hamaguchi Y, Yazawa N, et al. 2004. Autoantibodies to a collagen-specific molecular chaperone, heat-shock protein 47, in systemic sclerosis. Clin Exp Immunol, 138:534-9

Fujimoto M, Sato S. 2007. B cell signaling and autoimmune diseases: CD19/CD22 loop as a B cell signaling device to regulate the balance of autoimmunity. J Dermatol Sci, 46:1-9.

Furuse S, Fujii H, Kaburagi Y, et al. 2003. Serum concentrations of the CXC chemokines interleukin 8 and growth-regulated oncogene-alpha are elevated in patients with systemic sclerosis. J Rheumatol, 30:1524-8.

Gershwin ME, Abplanalp H, Castles JJ, et al. 1981. Characterization of a spontaneous disease of white leghorn chickens resembling progressive systemic sclerosis (scleroderma). $J$ Exp Med, 153:1640-59.

Goodnow CC. 1996. Balancing immunity and tolerance: deleting and tuning lymphocyte repertoires. Proc Natl Acad Sci USA, 93:2264-71.

Gruschwitz MS, Moormann S, Krömer G, et al. 1991. Phenotypic analysis of skin infiltrates in comparison with peripheral blood lymphocytes, spleen cells and thymocytes in early avian scleroderma. J Autoimmunity, 4:577-93.

Hasegawa M, Fujimoto M, Kikuchi K, et al. 1997. Elevated serum levels of interleukin 4 (IL-4), IL-10, and IL-13 in patients with systemic sclerosis. J Rheumatol, 24:328-32.

Hasegawa M, Hamaguchi Y, Yanaba K, et al. 2006. B-lymphocyte depletion reduces skin fibrosis and autoimmunity in the tight-skin mouse model for systemic sclerosis. Am J Pathol, 169:954-66.

Hu PQ, Fertig N, Medsger TA Jr, et al. 2003. Correlation of serum anti-DNA topoisomerase I antibody levels with disease severity and activity in systemic sclerosis. Arthritis Rheum, 48:1363-73.

Hussein MR, Hassan HI, Hofny ER, et al. 2005. Alterations of mononuclear inflammatory cells, CD4/CD8+ T cells, interleukin 1beta, and tumour necrosis factor alpha in the bronchoalveolar lavage fluid, peripheral blood, and skin of patients with systemic sclerosis. J Clin Pathol, 58:178-84.

Inaoki M, Sato S, Weintraub BC, et al. 1997. CD19-regulated signaling thresholds control peripheral tolerance and autoantibody production in B lymphocytes. $J$ Exp Med, 186:1923-31.

Jimenez SA, Derk CT. 2004. Following the molecular pathways toward an understanding of the pathogenesis of systemic sclerosis. Ann Intern Med, 140:37-51.

Kerhl JH, Roberts AB, Wakefield LM, et al. 1986. Transforming growth factor $\beta$ is an important immunomodulatory protein for human B lymphocytes. J Immunol, 137:3855-60.

Kurasawa K, Hirose K, Sano H, et al. 2000. Increased interleukin-17 production in patients with systemic sclerosis. Arthritis Rheum, 43:2455-63. 
Kuwana M, Okano Y, Kaburki J, et al. 1994. Racial differences in the distribution of systemic sclerosis-related serum antinuclear antibodies. Arthritis Rheum, 37:902-6.

Kuwana M, Kaburaki J, Arnett FC, et al. 1999. Influence of ethnic background on clinical and serologic features in patients with systemic sclerosis and anti-DNA topoisomerase I antibody. Arthritis Rheum, 42:465-74.

Kuwana M, Kaburaki J, Mimori T, et al. 2000. Longitudinal analysis of autoantibody response to topoisomerase 1 in systemic sclerosis. Arthritis Rheum, 43:1074-84.

Lafyatis R, O'Hara C, Feghali-Bostwick CA, et al. 2007. B cell infiltration in systemic sclerosis-associated interstitial lung disease. Arthritis Rheum, 56:3167-8.

Le Hir M, Martin M, Haas C, 1999. A syndrome resembling human systemic sclerosis (scleroderma) in MRL/lpr mice lacking interferon-gamma (IFN-gamma) receptor (MRL/lprgammaR-/-). Clin Exp Immunol, 115:281-7.

Lipsky PE. 2001. Systemic lupus erythematosus: an autoimmune disease of B cell hyperactivity. Nat Immunol, 2:764-6.

Looney RJ. 2002. Treating human autoimmune disease by depleting B cells. Ann Rheum Dis, 61:863-6.

Lunardi C, Bason C, Navone R, et al. 2000. Systemic sclerosis immunoglobulin $\mathrm{G}$ autoantibodies bind the human cytomegalovirus late protein UL94 and induce apoptosis in human endothelial cells. Nat Med, 6:1183-6

Matsushita T, Hasegawa M, Yanaba K, et al. 2006. Elevated serum BAFF levels in patients with Systemic Sclerosis: enhanced BAFF signaling in systemic sclerosis B lymphocytes. Arthritis Rheum, 54:192-201.

Mayes MD, Lacey JV Jr, Beebe-Dimmer J, et al. 2003. Prevalence, incidence, survival, and disease characteristics of systemic sclerosis in a large US population. Arthritis Rheum, 48:2246-55.

Meyer O. 2006. Prognostic markers for systemic sclerosis. Joint Bone Spine, 73:490-4.

O'Keefe TL, Williams GT, Batista FD, et al. 1999. Deficiency in CD22, a B cell - specific inhibitory receptor, is sufficient to predispose to development of high affinity autoantibodies. J Exp Med, 189:1307-13.

Phelps RG, Daian C, Shibata S, et al. 1993. Induction of skin fibrosis and autoantibodies by infusion of immunocompetent cells from tight skin mice into C57BL/6 Pa/Pa mice. J Autoimmun, 6:701-18.

Reveille JD, Fischbach M, McNearney T, et al. 2001. Systemic sclerosis in 3 US ethnic groups: a comparison of clinical, sociodemographic, serologic, and immunogenetic determinants. Semin Arthritis Rheum, 30:332-46.

Ruzek MC, Jha S, Ledbetter S, et al. 2004. A modified model of graft-versushost-induced systemic sclerosis (scleroderma) exhibits all major aspects of the human disease. Arthritis Rheum, 50:1319-31.

Saito S, Nishimura H, Phelps RG, et al. 2000. Induction of skin fibrosis in mice expressing a mutated fibrillin-1 gene. Mol Med, 6:825-36.

Saito E, Fujimoto M, Hasegawa M, et al. 2002. CD19-dependent B lymphocyte signaling thresholds influence skin fibrosis and autoimmunity in the tight-skin mouse. $J$ Clin Invest, 109:1453-62.

Sakkas LI. 2005. New developments in the pathogenesis of systemic sclerosis. Autoimmunity, 38:113-16.

Sato S, Hanakawa H, Hasegawa M, et al. 2000a. Levels of interleukin 12, a cytokine of type 1 helper T cells, are elevated in sera from patients with systemic sclerosis. $J$ Rheumatol, 27:2838-42.

Sato S, Hasegawa M, Fujimoto M, et al. 2000b. Quantitative genetic variation in CD19 expression correlates with autoimmunity. J Immunol, 165:6635-43.
Sato S, Hasegawa M, Takehara K. 2001. Serum levels of interleukin-6 and interleukin-10 correlate with total skin thickness score in patients with systemic sclerosis. J Dermatol Sci, 27:140-6.

Sato S, Fujimoto M, Hasegawa M, et al. 2004. Altered blood B lymphocyte homeostasis in systemic sclerosis: expanded naive $\mathrm{B}$ cells and diminished but activated memory B cells. Arthritis Rheum, 50:1918-27.

Schneider P, MacKay F, Steiner V, et al. 1999. BAFF, a novel ligand of the tumor necrosis factor family, stimulates B cell growth. J Exp Med, 189:1747-56.

Sgonc R, Gruschwitz MS, Dietrich H, et al. 1996. Endothelial cell apoptosis is a primary pathogenetic event underlying skin lesions in avian and human scleroderma. $J$ Clin Invest, 98:785-92.

Siracusa LD, McGrath R, Ma Q, et al. 1996. A tandem duplication within the fibrillin 1 gene is associated with the mouse tight skin mutation. Genom Res, 6:300-13.

Steen VD. 2005. Autoantibodies in systemic sclerosis. Semin Arthritis Rheum, 35:35-42.

Tan EM, Chan EKL, Sullivan KF, et al. 1988. Antinuclear antibodies (ANAs): diagnostically specific immune markers and clues toward the understanding of systemic autoimmunity. Clin Immunol Immupathol, 47:121-41.

Tedder TF, Inaoki M, Sato S. 1997. The CD19-CD21 complex regulates signal transduction thresholds governing humoral immunity and autoimmunity. Immunity, 6:107-18

Thien M, Phan TG, Gardam S, et al. 2004. Excess BAFF rescues self-reactive B cells from peripheral deletion and allows them to enter forbidden follicular and marginal zone niches. Immunity, 20:785-98.

Tsuchiya N, Kuroki K, Fujimoto M, et al. 2004. Association of a functional CD19 polymorphism with susceptibility to systemic sclerosis. Arthritis Rheum, 50:4002-7.

Varga J, Abraham D. 2007. Systemic sclerosis: a prototypic multisystem fibrotic disorder. $J$ Clin Invest, 117:557-67.

Van de Water J, Haapanen L, Boyd R, et al. 1989. Identification of T cells in early dermal lymphocytic infiltrates in avian scleroderma. Arthritis Rheum, 32:1031-40.

Verrecchia F, Laboureau J, Verola O, et al. 2007. Skin involvement in scleroderma - where histological and clinical scores meet. Rheumatology, 46:833-41.

Whitfield ML, Finlay DR, Murray JI, et al. 2003. Systemic and cell typespecific gene expression patterns in scleroderma skin. Proc Natl Acad Sci USA, 100:12319-24.

Wynn TA. 2004. Fibrotic disease and the $\mathrm{T}(\mathrm{H}) 1 / \mathrm{T}(\mathrm{H}) 2$ paradigm. Nat Rev Immunol, 4:583-94.

Yamamoto T, Takagawa S, Katayama I, et al. 1999. Animal model of sclerotic skin. I. Local injections of bleomycin induce sclerotic skin mimicking scleroderma. J Invest Dermatol, 112:456-62.

Yamamoto T. 2006. The bleomycin-induced scleroderma model: what have we learned for scleroderma pathogenesis? Arch Dermatol Res, 297:333-44

Youinou P. 2007. B cell conducts the lymphocyte orchestra. J Autoimmun, 28:143-51.

Young-Min SA, Beeton C, Laughton R, et al. 2001. Serum TIMP-1, TIMP-2, and MMP-1 in patients with systemic sclerosis, primary Raynaud's phenomenon, and in normal controls. Ann Rheum Dis, 60:846-51.

Zhou X, Tan FK, Milewicz DM, et al. 2005. Autoantibodies to fibrillin-1 activate normal human fibroblasts in culture through the TGF- $\beta$ pathway to recapitulate the "Scleroderma phenotype". J Immunol, 175:4555-60. 
